\title{
Abdominal aorta calcifications in patients with kidney stones, is there a link?
}

\section{Calcificaciones de la aorta abdominal en pacientes con litiasis renal, ¿existe un vínculo?}

\author{
Mario Basulto-Martínez, ${ }^{*}$ (1) Guillermo José Cueto Vega, ${ }^{1}$ Amanda Elisa Arenas-Aquino, ${ }^{1}$ \\ (1) José Enrique Espinosa Aznar, ${ }^{1}$ Dalia Montserrat Meza-Bosquez, ${ }^{2}$ (Dodrigo Ortegón-Gallareta, ${ }^{2}$ \\ CAntonio Esqueda-Mendoza, ${ }^{1}$ - Juan Pablo Flores Tapia. ${ }^{1}$
}

Keywords:

Kidney stones;

urolithiasis; kidney

calculi; hypertension;

hypocitraturia

Corresponding author:

*Mario Basulto-

Martínez. Calle 7 por

20 y 22 Núm. 433,

Fraccionamiento

Altabrisa, Mérida,

Yucatán. C.P. 97130.

Correo electrónico:

basultourologia@gmail.

com

\section{Abstract}

Objective: To investigate the correlations between abdominal aortic calcifications (AAC) and the underlying urinary metabolic abnormalities in stone-formers (SF).

Methods: Patients with a $24 \mathrm{~h}$ urinary panel and computed tomography scan were included. The Kauppila Score (KS) was used to quantitatively assess AAC; clinical data and stone information were also recorded. The Spearman correlation was utilized.

Results: A total of 54 patients were included, the mean age was $46.4 \pm 11.2$, $75.9 \%$ were female, and $59.3 \%$ had AAC. Hypertension and AAC were associated ( $\mathrm{p}=0.026$ ), and the KS was higher in patients with hypertension. Hypocitraturia $(98.1 \%)$ and hypercalciuria $(16.7 \%)$ were the most frequent urinary abnormalities, but they were unrelated to AAC ( $p>0.05$ ). The 24 urinary panel, blood biochemistry, stone burden and hardness, and body mass index were not correlated to the KS ( $p>0.05)$.

Limitations: This work had the following limitations: its retrospective nature, a relatively small sample, and the lack of an automated informatics-based assessment of AAC.

Conclusion: The link between cardiovascular diseases and kidney stones is still to be elucidated. Our finding differs from the other few studies reported on the literature, as no correlation was found between AAC and the urinary metabolic abnormalities in SF.

Citation: Basulto-Martínez M., Cueto-Vega G. J., Arenas-Aquino A. E., Espinosa-Aznar J. E., Meza-Bosquez D. M., Ortegón-Gallareta R, et al. Abdominal aorta calcifications in patients with kidney stones, is there a link? Rev Mex Urol. 2022;82(1):pp. 1-11

${ }^{1}$ Secretaría de Salud, Hospital Regional de Alta Especialidad de la Península de Yucatán, Yucatán, México.

${ }^{2}$ Escuela de Medicina, Universidad Anáhuac Mayab, Yucatán, México.

Received: 28 de diciembre de 2020 Accepted: 14 de enero de 2022

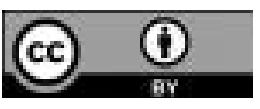




\section{Abdominal aorta calcifications in patients with kidney stones, is there a link? Basulto-Martínez M., et al.}

\section{Resumen}

Objetivo: Investigar la correlación entre la calcificación aórtica abdominal (AAC) y las alteraciones urinarias metabólicas subyacentes en formadores de litiasis (SF).

Métodos: Pacientes con perfil metabólico urinario de 24 hrs y tomografía computarizada fueron incluidos. Se utilizó el índice de Kauppila (KS) para el análisis cuantitativo de las AAC; y se recabaron datos clínicos y características del lito. Se empleó la prueba de correlación de Spearman.

Resultados: Se incluyeron 54 pacientes, con media de edad de $46.4 \pm 11.2,75.9 \%$ fueron mujeres y el 59.3\% tuvo AAC. La hipertensión y las AAC estuvieron asociadas $(p=0.026)$, y el KS fue mayor en pacientes hipertensos. La hipocitraturia (98.1\%) e hipercalciuria (16.7\%) fueron las alteraciones urinarias más frecuentes, pero no se relacionaron con las AAC ( $p>0.05)$. El perfil metabólico urinario, pruebas bioquímicas, dureza y carga litiásica y el índice de masa corporal no presentaron correlación con el KS ( $p>0.05$ ).

Limitaciones del estudio: El trabajo cursa con limitaciones tal como la naturaleza retrospectiva, una muestra pequeña y la falta evaluación automatizada de las calcificaciones en la aorta abdominal.

Conclusión: El vínculo entre las enfermedades cardiovasculares y la litiasis renal necesita ser aclarado. Nuestros resultados contrastan con los poco reportados en la literatura, ya que no encontramos correlación entre las AAC y las alteraciones metabólicas urinarias SF.

\section{Introduction}

The prevalence of kidney stones has been steadily increasing worldwide and this increase has been more pronounced in undeveloped countries. $^{(1,2)}$ This recurrent disease has a negative impact on patients' quality of life, and can progress to kidney function impairment. The environmental and lifestyle risk factors for the development of kidney stones have been highlighted extensively. Furthermore, genetic alterations associated with the underlying urinary metabolic abnormalities that lead to kidney stones, have also been described in recent years. ${ }^{(3-5)}$

Assessing the stone-formers (SF) urinary metabolism is paramount, as it reflects, to an extent, dietary habits which provide information on hydration and acid-base status. Certain substances in urine work, whether as inhibitors or facilitators of stone aggregation and nucleation, the first steps of lithogenesis. In average subjects, urine is virtually always metastable to calcium oxalate and other substances ${ }^{(6)}$ Keeping those substances balanced is among the most important recurrence-prevention strategies, and these alterations can be detected trough a $24 \mathrm{~h}$ urinary panel (24UP), giving place to tailored managements to restore such balance based on diet, supplements and/or drugs.

On the other hand, a link between metabolic diseases and kidney stones has been suggested. Recently, the pathophysiological pathways through which type 2 diabetes and insulin resistance turn out in more acidic urine have been 
outlined, resulting in a higher risk for kidney stones. ${ }^{(7,8)}$ Mexico is considered as the country with the highest prevalence of obesity; in Southeast Mexico, the prevalence of overweight/obesity is $72.5 \% .^{(9)}$ Likewise, a high prevalence of type 2 diabetes (9.2\%) and hypertension (25.5\%) was reported locally in the most recent National Health and Nutrition Survey. ${ }^{(10,11)}$ Moreover, hypertension and coronary artery disease, which have a risk relation with obesity and type 2 diabetes, have also been related to kidney stones. ${ }^{(8)}$ Although the link remains unclear, hypertension is more prevalent in SF than in subjects without kidney stones. ${ }^{(12,13)}$

Endothelial dysfunction and atherosclerosis are associated to oxidative stress, which is a common pathway for kidney stones development. ${ }^{(14)}$ Furthermore, vascular calcifications, especially abdominal aortic calcifications (AAC), serves as an indicator of vascular damage and mortality. ${ }^{(15)}$ Recently, Patel et al. reported that SF with AAC had lower urinary citrate and $\mathrm{pH} .{ }^{(16)}$ In this work we aimed to assess the relation of AAC and the 24UP in SF.

\section{Material and methods}

This study was approved by the Ethics and Research Committees from the Hospital Regional de Alta Especialidad de la Península de Yucatán. The prospectively collected database, comprising data of SF treated at the Hospital Stone Clinic was retrospectively reviewed. Patients who met the following criteria were included: (i), 18 years or older; (ii), complete medical record; (iii), digital images from a non-contrast computed tomography (NCCT) scan; (iv), a 24UP including urinary calcium, citrate and $\mathrm{pH}$, and blood tests including glucose, creatinine, calcium, vitamin D and PTH.

\section{NCCT assessment}

Every NCCT scan was independently assessed by two urologists (MBM, AEAA), from which the following data was retrieved: stone burden, Hounsfield Units (HU) and whether any AAC was present. For AAC quantitative assessment, the Kauppila Score (KS) was utilized, in which the abdominal aorta is axially split into four, matching the vertebral L1-L4 levels, and then coronally into anterior and posterior, resulting in 8 sections. Each section is assesed for AAC and graded according to the calcifications observed as follows: 0 , no calcifications; 1 , up to $1 / 3$ of the section; 2 , beyond $1 / 3$ of the section; 3 , beyond $2 / 3$ of the section. Finally, all of the sections' values are added to obtain the KS, which ranges between 0-24 (figure 1). ${ }^{(17)}$ 
Figure 1. Kauppila Score for quantitative assessment of the abdominal aortic calcifications
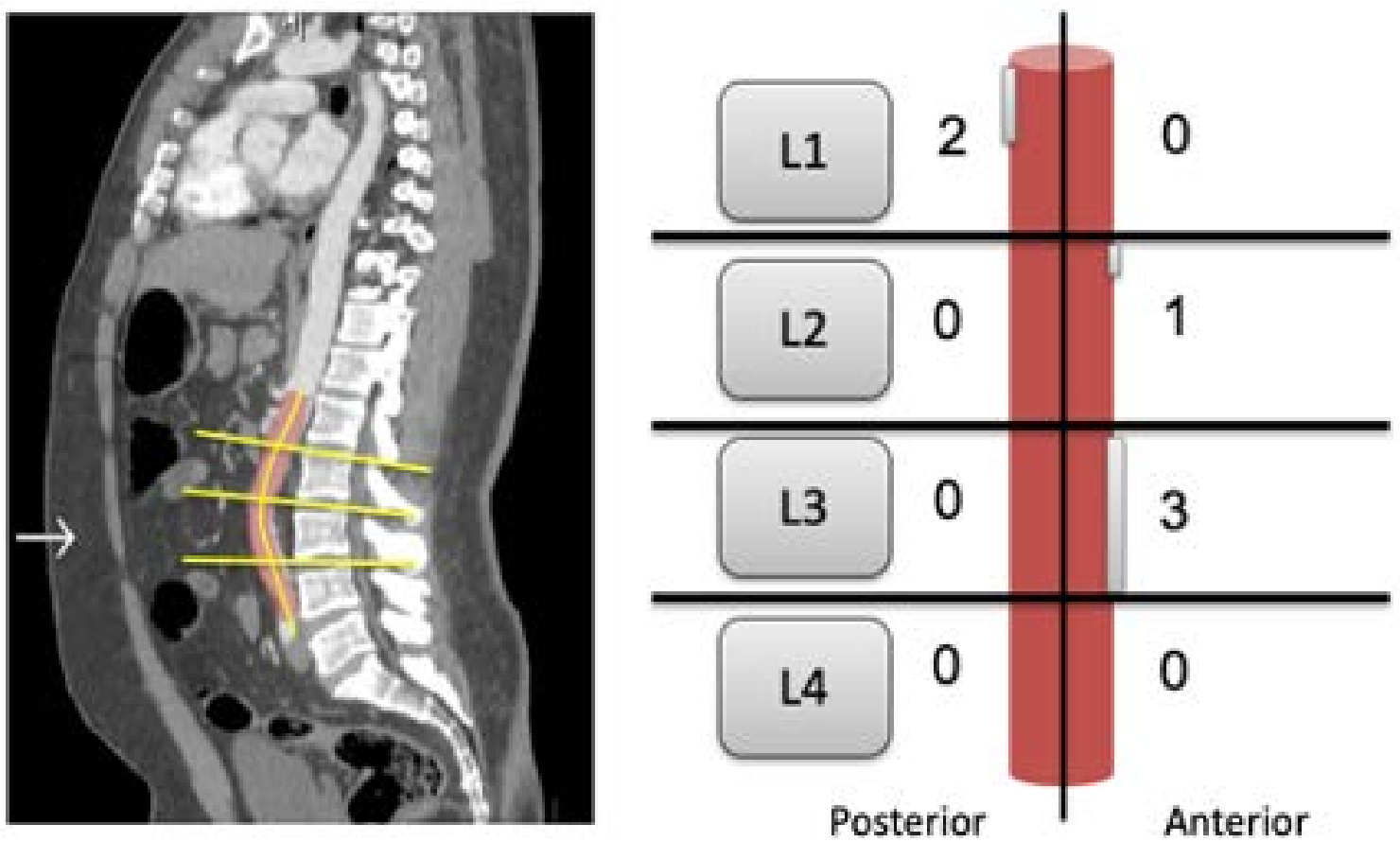

Eight sections are obtained by splitting the abdominal aorta axially in the L1-L4 vertebral levels, ${ }^{(4)}$ which are then again divided into anterior and posterior sections. ${ }^{(8)}$ Each of the 8 sections is assessed for calcifications, and a 0-3 score is given as follows: 0 , no calcifications; 1 , up to $1 / 3 ; 2$, more than $1 / 3 ; 3$, more than $2 / 3$. Then, all the sections values are added to get a final score between 0 and 24. The image provides an example of a score of 1 (L2 anterior), plus 2 (L1 posterior), and 3 (L3 anterior), thus a total Kauppila Score of 6.

\section{Biochemical analysis}

Urine and blood samples from all patients were processed at the hospital clinical laboratory and the following methods were used: calcium, ionic method; $\mathrm{pH}$, potentiometry; citrate and glucose, enzymatic standardized methods; vitamin D and PTH, chemiluminescent method.

\section{Statistical analysis}

All analyses were conducted through the Statistical Package for the Social Sciences (SPSS Inc., V. 21, Chicago, IL). The categorical data was presented as frequencies, whereas quantitative data was presented as mean \pm standard deviation or median (percentiles 25th -75 th) according to its distribution, tested by the Kolmogorov-Smirnov method. Calcium/creatinuria and citrate/creatinuria urinary ratios were calculated to avoid the kidney function's effect. The categorical data was compared through $X^{2}$ test and the quantitative data by a $T$-test or $U$-Mann-Whitney test, as appropriate. The Spearman test was used for correlations. P values of $<0.05$ were considered significant. 


\section{Results}

A total of 54 patients met the criteria and were included in the study. The mean age was $46.4 \pm 11.2$, AAC were observed in $59.3 \%$, and $75.9 \%$ of the patients were female. Patients' characteristics and demographics are presented in table 1 . The KS was 3 (2-5.7) and it was moderately correlated with age $(\mathrm{p}<0.001, \mathrm{r}=0.48)$. Moreover, hypertension and AAC were associated $(\mathrm{p}=0.026)$, as $76.5 \%$ of hypertense patients had AAC; and the KS was higher in patients with hypertension [4 (2-8) vs 2 $(2-4), \mathrm{p}=0.026]$.

Table 1. Initial characteristics and demographics of stone-formers

\begin{tabular}{|c|c|}
\hline Gender (\%) & \\
\hline Male & 24.1 \\
\hline Female & 75.9 \\
\hline Age & $46.4 \pm 11.2$ \\
\hline BMI $\left(\mathrm{kg} / \mathrm{m}^{2}\right)$ & $31.4 \pm 5.2$ \\
\hline Hypertension (\%) & 31.5 \\
\hline Type 2 diabetes (\%) & 20.4 \\
\hline AAC (\%) & 59.3 \\
\hline Kauppila Score & $3(2-5.7)$ \\
\hline Stone burden $\left(\mathrm{cm}^{3}\right)$ & $8.5(4-14.2)$ \\
\hline $\mathrm{HU}$ & $1002(631.7-1279.6)$ \\
\hline Glycemia $(\mathrm{mg} / \mathrm{dL})$ & $95.9(89.4-106.5)$ \\
\hline Urea, serum (mg/dL) & $38.2(22.7-57.6)$ \\
\hline Creatinine, serum (mg/dL) & $1.09(0.80-1.82)$ \\
\hline Calcium, serum $(\mathrm{mg}(\mathrm{dL})$ & $8.9(8.3-9.4)$ \\
\hline Urinary calcium (mg/24h) & $115.4(53.8-168.2)$ \\
\hline Creatinuria (mg/24h) & $65(39.5-142.2)$ \\
\hline Urinary volume $(\mathrm{ml} / 24 \mathrm{~h})$ & $2147.5(1697.5-2797.5)$ \\
\hline PTH $(\mathrm{pg} / \mathrm{mL})$ & $46.4(25.1-74.9)$ \\
\hline Vitamin D (pg/mL) & $22.7(17.4-31)$ \\
\hline Urinary pH & $6(5-7)$ \\
\hline
\end{tabular}

AAC, Abdominal aortic calcifications; BMI, body mass index; HU, Hounsfield Units.

Hypocitraturia ( $<320 \mathrm{mg} / 24 \mathrm{~h}$ ) and hypercalciuria ( $>200 \mathrm{mg} / 24 \mathrm{~h}$ ) were observed in $98.1 \%$ and $16.7 \%$ of the patients, respectively, and no association with AAC was found ( $\mathrm{p}=0.403 \mathrm{y} \mathrm{p}=0.620$, respectively). Table 2 shows a comparison between SF with, and without AAC. No correlations between the KS and 24UP, blood analytes, stone burden, HU and body mass index (BMI) were found (all $\mathrm{p}>0.05$ ). 
Table 2. Differences between stone-formers with and without abdominal aortic calcifications

\begin{tabular}{|c|c|c|c|}
\hline & $A A C$ & No AAC & P \\
\hline Age & $50.5(43.2-57.7)$ & $41.5(34.7-49.2)$ & $0.004^{*}$ \\
\hline \multicolumn{4}{|l|}{ Gender (\%) } \\
\hline \multicolumn{4}{|l|}{ - Male } \\
\hline \multicolumn{4}{|l|}{ - Female } \\
\hline \multicolumn{4}{|l|}{34.4} \\
\hline \multicolumn{4}{|l|}{65.6} \\
\hline \multicolumn{4}{|l|}{9.1} \\
\hline 90.9 & $0.033^{*}$ & & \\
\hline BMI $\left(\mathrm{Kg} / \mathrm{m}^{2}\right)$ & $31.1(28.6-35.4)$ & $31.6(26.6-35.7)$ & 0.867 \\
\hline Hypertension (\%) & 40.6 & 18.2 & $0.026^{*}$ \\
\hline Type 2 diabetes (\%) & 25 & 13.6 & 0.308 \\
\hline Hypocitraturia (\%) & 96.9 & 100 & 0.403 \\
\hline Hypercalciuria (\%) & 18.8 & 13.6 & 0.620 \\
\hline Stone burden $\left(\mathrm{cm}^{3}\right)$ & $8.6(4.8-14.7)$ & $8.3(3.1-14.1)$ & 0.712 \\
\hline HU & $1037.5(654.7-1315.1)$ & $984(626.2-1246.4)$ & 0.460 \\
\hline Glycemia (mg/dL) & $97.6(91.5-107.7)$ & $94.7(86.3-104.6)$ & 0.439 \\
\hline Urea, serum (mg/dL) & $38.2(28.3-56.6)$ & $35.2(20.7-69.1)$ & 0.509 \\
\hline Creatinine, serum (mg/dL) & $1.09(0.82-1.69)$ & $1.07(0.75-2.80)$ & 0.874 \\
\hline Calcium, $\operatorname{serum}(\mathrm{mg} / \mathrm{dL})$ & $8.95(8.40-9.50)$ & $8.65(8.17-9.32)$ & 0.481 \\
\hline Vitamin D (pg/mL) & $22.7(19-32)$ & $22.4(15.3-30.6)$ & 0.470 \\
\hline PTH (pg/mL) & $43.7(25-80.9)$ & $51.7(26-69)$ & 0.826 \\
\hline Urinary volume $(\mathrm{ml} / 24 \mathrm{~h})$ & $2228.5(1900.5-2886)$ & $2020(1182.5-2720)$ & 0.117 \\
\hline Creatinuria (mg/24h) & $1.17(0.87-1.40)$ & $1.06(0.85-1.18)$ & 0.315 \\
\hline Urinary pH & $6(5-6.9)$ & $6(5-7)$ & 0.870 \\
\hline Urinary citrate (mg/24h) & $70(36.5-140)$ & $59(40.8-165.8)$ & 0.895 \\
\hline Urinary calcium (mg/24h) & $123.6(61-177.3)$ & $95.2(50.15-168.2)$ & 0.374 \\
\hline calcium/creatinuria ratio & $0.14(0.07-0.18)$ & $0.10(0.04-0.18)$ & 0.549 \\
\hline citrate/creatinuria ratio & $59.4(31-119.7)$ & $65.5(35.7-197.1)$ & 0.476 \\
\hline
\end{tabular}

AAC, Abdominal aortic calcifications; BMI, body mass index; HU, Hounsfield Units.*Statistically significant

\section{Discussion}

Nephrolithiasis is a public health challenge, as it overburdens health care services due to its recurrent nature and spreading generic preventive recommendations which suit all types of stones is not always feasible, because of the phenotype complexity. Therefore, the generation of information regarding the pathophysiological pathways implied is highly appreciated, as it can serve as a beacon for guiding further research, and strategies which provide founda- 
tions for more robust and personalized recommendations. In recent years, the prevalence of kidney stones has been increasing, and it has been suggested as a result of the parallel prevalence increase of metabolic diseases, such as obesity, diabetes and hypertension.

Other studies have associated hypertension and kidney stones; a link that was first described by Tibblin in the 1960's. ${ }^{(18)}$ Similarly, Borghi et al., found that patients with hypertension had higher incidence of stone episodes when compared with subjects without hypertension (14 vs $3 \%){ }^{(19)}$ Despite the causal relationship being unclear, shared factors between urolithiasis and hypertension have been described. Shang et al., suggested that calcium metabolism might play a role in the pathogenesis of both diseases; then, they suggested that the components of the metabolic syndrome, which are also highly prevalent in patients with urolithiasis and/or hypertension, might signal to insulin resistance as a common pathophysiological pathway. Hence, patients with urolithiasis and/or hypertension are more likely to develop chronic kidney disease. Finally, inflammation and oxidative stress have also been recently suggested as possible link. ${ }^{(13)}$ Inflammation can cause renal vasoconstriction, ischemia, and injury, rising blood pressure. Likewise, inflammation and oxidative stress can damage epithelial renal cells, becoming exposed to crystallization in the collecting ducts. Thus, observational studies have shown hypertension as a predictive factor for the recurrence of kidney stones. ${ }^{(20-22)}$

AAC are observed in over $80 \%$ of patients $>65$ years-old, and this condition has been proposed as a predictor for cardiovascular events and mortality, and quantitative scores have been reported. Kauppila et al., retrieved data from the Framingham cohort and developed a score based on calcification severity assessed by its extension. As this score was first reported on $\mathrm{x}$-ray, no information on attenuation is considered. ${ }^{(17)}$

Our study showed that hypertension has a role in the risk of kidney stones development, but the causality link is yet to be elucidated. However, in SF, the prevalence of hypertension (31.5\%) and type 2 diabetes (20.4\%), exceeds the one reported in Mexico's Southeast overall population (13.6\% and $9.2 \%$, respectively; both $\mathrm{p}<0.05)$. Moreover, the prevalence of hypertension was higher in SF with AAC (table 2) and the KS was higher in SF with hypertension $(\mathrm{p}=0.026)$.

Other studies have addressed these aspects and are enlisted in table 3. A high prevalence of hypertension in SF in Ohio (67\%) was reported by Patel et al., and it was also significantly higher in SF with AAC (85.5\%). ${ }^{(16)}$ Likewise, a higher prevalence of type 2 diabetes was reported in SF with AAC, which was not observed in our study. Similarly, Shavit et al. conducted a retrospective case-control study and found that hypertension was more prevalent in SF than in non-stone-former controls $(10 \%$ vs $2 \%, \mathrm{p}=0.002)$, but the frequency of type 2 diabetes was comparable ( $35 \%$ vs $9 \%, \mathrm{p}=0,07$ ). Even though no sub-analysis was conducted between patients with AAC, a comparable rate was reported between SF (38\%) and control subjects (35\%). These outcomes showed that older age and male sex were associated with ACC. According to that, at least up to one third of SF has a previous history of hypertension, and this holds a relation with AAC, which are observed in $38-64 \%{ }^{(23)}$ 





Abdominal aorta calcifications in patients with kidney stones, is there a link? Basulto-Martínez M., et al.

The similarities between our outcomes and those reported by Patel et al., might respond in part to the high BMI found in both populations. However, the overall lower hypertension rate might be explained by the younger population reported here (table 3 ). Interestingly, our cohort had larger stone-burden, but the meaning of this finding is yet to be explored. Furthermore, we did not find any correlation between urinary metabolism and AAC. The work by Patel et al., reports that urinary $\mathrm{pH}$ and citrate were lower, and stone burden was higher in SF with AAC. Moreover, $80 \%$ of uric acid SF had AAC. This finding is consistent with the pathophysiological pathway of impaired ammonia excretion due to insulin resistance in obesity, which turns out in more acidic urine (low $\mathrm{pH}$, low citrate), facilitating the aggregation of uric acid stones, but also calcium-containing stones. Interestingly, the higher proportion of AAC was observed among uric acid SF, suggesting a common link between vascular calcifications, hypertension and kidney stones. ${ }^{(16)}$

We did not find any correlation between 24UP and AAC, contrasting with the results of Patel et al., who reported a correlation with urinary citrate and $\mathrm{pH}$ and AAC. Regarding citrate, an explanation is the high prevalence and severity of hypocitraturia reported in Southeast Mexico. Hence, this work has a low proportion of SF without hypocitraturia $(<2 \%)$, which hinders comparisons, as we mostly faced a hypocitraturic SF cohort.

A possible role of vascular diseases in kidney stones is undeniable, as cumulative evidence points toward this direction. Ne- vertheless, the link still needs to be explored. Obesity and vascular diseases have common backgrounds which might be evident as AAC, and somehow serve as an indicator for the urinary metabolism of SF. However, this study did not find any correlation between AAC and urinary calcium, citrate and $\mathrm{pH}$, but further prospective case-control studies are warranted.

This work has the following limitations: (i), its retrospective nature; (ii), a relatively small sample; (iii), the lack of an automated informatics-based assessment of AAC.

\section{Conclusions}

The search for a pathophysiological link between obesity, cardiovascular diseases and kidney stones is sure to bring clinically impactful outcomes. As the association of these diseases increases, the causality is still to be determined. However, even if AAC, which indicate vascular disease, somehow reveal SF's urinary metabolisms, it remains controversial and further endeavors are needed.

\section{Financing:}

No sponsorship was received to write this article.

\section{Conflict of interest:}

The authors declare no conflicts of interest. 


\section{Abdominal aorta calcifications in patients with kidney stones, is there a link? Basulto-Martínez M., et al.}

\section{References}

1. Romero V, Akpinar H, Assimos DG. Kidney stones: a global picture of prevalence, incidence, and associated risk factors. Rev Urol. 2010;12(23):e86-96.

2. Yasui T, Okada A, Hamamoto S, Ando R, Taguchi K, Tozawa K, et al. Pathophysiologybased treatment of urolithiasis. International Journal of Urology. 2017;24(1):32-8. doi: 10.1111/iju.13187

3. Basulto-Martínez M, Olvera-Posada D, Velueta-Martínez IA, Méndez-Probst C, Flores-Tapia JP, Penniston K, et al. Quality of life in patients with kidney stones: translation and validation of the Spanish Wisconsin Stone Quality of Life Questionnaire. Urolithiasis. 2020;48(5):419-24. doi: 10.1007/s00240-02001192-9

4. Smith AK. Campbell-Walsh Urology. In: Wein A, ed. Campbell-Walsh Urology. 11th ed. Philadelphia: Elsevier; 2016:1170-1299

5. Alelign $\mathbf{T}$, Petros B. Kidney Stone Disease: An Update on Current Concepts. Adv Urol. 2018;2018:3068365. doi: $10.1155 / 2018 / 3068365$

6. Ratkalkar VN, Kleinman JG. Mechanisms of Stone Formation. Clin Rev Bone Miner Metab. 2011;9(3-4):187-97. doi: 10.1007/s12018011-9104-8

7. Taylor EN, Stampfer MJ, Curhan GC. Obesity, Weight Gain, and the Risk of Kidney Stones. JAMA. 2005;293(4):455-62. doi: 10.1001/ jama.293.4.455

8. Taylor EN, Stampfer MJ, Curhan GC. Diabetes mellitus and the risk of nephrolithiasis. Kidney Int. 2005;68(3):1230-5. doi: 10.1111/j.15231755.2005.00516.X

9. Shamah-Levy T, Campos-Nonato I, CuevasNasu L, Hernández-Barrera L, Morales-Ruán
M del C, Rivera-Dommarco J, et al. Sobrepeso y obesidad en población mexicana en condición de vulnerabilidad. Resultados de la Ensanut 100k. Salud Pública de México. 2019;61(6, novdic):852-65. doi: 10.21149/10585

10. Rojas-Martínez R, Basto-Abreu A, AguilarSalinas CA, Zárate-Rojas E, Villalpando S, Barrientos-Gutiérrez T. Prevalencia de diabetes por diagnóstico médico previo en México. Salud Pública de México. 2018;60(3, may-jun):224-32. doi: 10.21149/8566

11. Campos-Nonato I, Hernández-Barrera L, Pedroza-Tobías A, Medina C, Barquera S. Hipertensión arterial en adultos mexicanos: prevalencia, diagnóstico y tipo de tratamiento. Ensanut MC 2016. Salud Pública de México. 2018;60(3, may-jun):233-43. doi: $10.21149 / 8813$

12. Cupisti A, D’Alessandro C, Samoni S, Meola M, Egidi MF. Nephrolithiasis and hypertension: possible links and clinical implications. J Nephrol. 2014;27(5):477-82. doi: 10.1007/ s40620-014-0068-X

13. Shang W, Li Y, Ren Y, Yang Y, Li H, Dong J. Nephrolithiasis and risk of hypertension: a meta-analysis of observational studies. BMC Nephrology. 2017;18(1):344. doi: 10.1186/ s12882-017-0762-8

14. Saeed R. Khan. Is oxidative stress, a link between nephrolithiasis and obesity, hypertension, diabetes, chronic kidney disease, metabolic syndrome? Urol Res. 2012 Apr;40(2):95-112. doi: 10.1007/s00240-011-0448-9

15. An C, Lee H-J, Lee HS, Ahn SS, Choi BW, Kim M-J, et al. CT-based abdominal aortic calcification score as a surrogate marker for predicting the presence of asymptomatic coronary artery disease. Eur Radiol. 2014;24(10):2491-8. doi: 10.1007/s00330-0143298-3 
16. Patel ND, Ward RD, Calle J, Remer EM, Monga M. Vascular Disease and Kidney Stones: Abdominal Aortic Calcifications Are Associated with Low Urine $\mathrm{pH}$ and Hypocitraturia. Journal of Endourology. 2017;31(9):956-61. doi: 10.1089/end.2017.0350

17. Kauppila LI, Polak JF, Cupples LA, Hannan MT, Kiel DP, Wilson PWF. New indices to classify location, severity and progression of calcific lesions in the abdominal aorta: a 25-year followup study. Atherosclerosis. 1997;132(2):245-50. doi: 10.1016/S0021-9150(97)00106-8

18. Tibblin G. A Population Study of 50-yearold Men. Acta Medica Scandinavica. 1965;178(4):453-9. doi: 10.1111/j.09546820.1965.tb04290.X

19. Borghi L, Meschi T, Guerra A, Briganti A, Schianchi T, Allegri F, et al. Essential arterial hypertension and stone disease. Kidney Int. 1999;55(6):2397-406. doi: 10.1046/j.15231755.1999.00483.x
20. Montecucco F, Pende A, Quercioli A, Mach F. Inflammation in the pathophysiology of essential hypertension. J Nephrol. 2011;24(1):23-34. doi: 10.5301/jn.2010.4729

21. Coe FL, Evan AP, Worcester EM, Lingeman JE. Three pathways for human kidney stone formation. Urol Res. 2010;38(3):147-60. doi: 10.1007/s00240-010-0271-8

22. Kim Y-J, Park MS, Kim W-T, Yun S-J, Kim W-J, Lee S-C. Hypertension influences recurrent stone formation in nonobese stone formers. Urology. 2011;77(5):1059-63. doi: 10.1016/j. urology.2010.07.492

23. Shavit L, Girfoglio D, Vijay V, Goldsmith D, Ferraro PM, Moochhala SH, et al. Vascular Calcification and Bone Mineral Density in Recurrent Kidney Stone Formers. CJASN. 2015;10(2):278-85. doi: 10.2215/ CJN.06030614 